\title{
Theoretical Study and X-ray Determination of Bianthrones: Long C-C Bond Length and Preferred Gauche Conformation
}

\author{
Pai-Chi Li, ${ }^{\dagger, \ddagger}$ Tsung-Shing Wang, ${ }^{\dagger}$ Gen-Hsian Lee, ${ }^{\dagger}$ Yi-Hong Liu, $^{\dagger}$ Yu Wang, ${ }^{*, \dagger}$ \\ Chao-Tsen Chen, ${ }^{*,+}$ and Ito Chao*,‡ \\ Department of Chemistry, National Taiwan University, Taipei, Taiwan, R.O.C., and Institute of \\ Chemistry, Academia Sinica, Taipei, Taiwan, R.O.C. \\ ichao@chem.sinica.edu.tw; chenct@ccms.ntu.edu.tw
}

Received March 21, 2002

\begin{abstract}
Five X-ray crystallographic structures of bianthrones $(\mathbf{1}, \mathbf{2 b}-\mathbf{5 b})$ revealed the presence of long central $\mathrm{C}\left(\mathrm{sp}^{3}\right)-\mathrm{C}\left(\mathrm{sp}^{3}\right)$ bonds $(\geq 1.60 \AA)$ and mostly gauche conformation. DFT calculations were carried out to study the structural features of bianthrones and related model molecules. Our B3LYP/ 6-31G* gas-phase calculation results suggest that steric effect plays a role in causing the long $\mathrm{C}-\mathrm{C}$ $\sigma$ bond length $(>1.60 \AA)$, nonplanarity of the anthracenone moiety $\left(>20^{\circ}\right)$, and preferred gauche conformation. However, when the gauche preference is weak, environmental effects such as solvation and packing forces can reverse it. As the degree of nonplanarity of the anthracenone moiety is consistently larger in the anti conformation than in the gauche and the ease of achieving nonplanarity is determined by flexibility of the central six-membered rings directly connected to the $\mathrm{C}\left(\mathrm{sp}^{3}\right)-\mathrm{C}\left(\mathrm{sp}^{3}\right)$ bond, one way to control the structure and anti-gauche energy difference of closely related compounds is by changing the clamping group $(Z)$ in the central six-membered ring.
\end{abstract}

\section{Introduction}

Bianthrones are potential structural elements in the design of supramolecular systems. We have synthesized substituted bianthrones by reduction of substituted 9,10anthraquinones promoted by zinc dust in the presence of aqueous ammonia. It is shown in Scheme 1 that a disubstituted 9,10-anthraquinone $(\mathbf{2 a}-\mathbf{5 a})$ can be reduced to $1,1^{\prime}, 8,8^{\prime}$-tetrasubstituted/4,4',5,5'-tetrasubstituted 9,9'-bianthracene-10,10' $\left(9 \mathrm{H}, 9^{\prime} \mathrm{H}\right)$-dione ( $\mathbf{2} \mathbf{b}-\mathbf{5} \mathbf{b}$; also termed as bianthrone), 1,8-disubstituted/4,5-disubstituted anthracen-9(10H)-one (2c-5c), and 1,8-disubstituted anthracene $(\mathbf{2 d}-\mathbf{5 d}) .{ }^{1}$ Product distributions of these reduction reactions warrant further study to explain the product ratio and regioselectivity. In this article we focus on the structural features of bianthrones, due to their relevance in application of bianthrones in supramolecular chemistry.

The interesting structural features we found in bianthrones are (1) the central $\mathrm{C}\left(\mathrm{sp}^{3}\right)-\mathrm{C}\left(\mathrm{sp}^{3}\right)$ bonds are longer than $1.6 \AA$ in the X-ray structures and (2) the X-ray structures are mostly in the gauche conformation, with the conformation defined by the dihedral angle $\mathrm{H}-\mathrm{C}\left(\mathrm{sp}^{3}\right)-$ $\mathrm{C}\left(\mathrm{sp}^{3}\right)-\mathrm{H}$. The $\mathrm{C}\left(\mathrm{sp}^{3}\right)-\mathrm{C}\left(\mathrm{sp}^{3}\right)$ bond lengths in bianthrones are no comparison to the long $\mathrm{C}\left(\mathrm{sp}^{3}\right)-\mathrm{C}\left(\mathrm{sp}^{3}\right)$ bond $(1.72$ $\AA$ ) observed in strained 3,8-dichloro-1,1,2,2-tetraphenylcyclobuta[b]naphthalene. ${ }^{2}$ They are also shorter than

\footnotetext{
† National Taiwan University.

₹ Academia Sinica.

(1) Formation of bianthrones has been elusive to previous observations under similar reaction condition.

(2) (a) Toda, F.; Tanaka, K.; Sano, I.; I sozaki, T. Angew. Chem., Int. Ed. Engl. 1994, 33, 1757. (b) Toda, F.; Tanaka, K.; Stein, Z.; Goldberg, I. Acta Crystallogr. Sect. C 1996, 52, 177.
}

those in hexaphenyl ethane and hexaal kyl ethane (1.64$1.67 \AA$ ).${ }^{3}$ Neverthel ess, compared to similar tetrasubstituted $\mathrm{C}\left(\mathrm{sp}^{3}\right)-\mathrm{C}\left(\mathrm{sp}^{3}\right)$ bonds that are not part of a strained ring and are connected to aromatic moieties, this bond length is clearly long. For example, the $\mathrm{C}\left(\mathrm{sp}^{3}\right)-\mathrm{C}\left(\mathrm{sp}^{3}\right)$ bond length of phenyl-unclamped 1,1,2,2-tetraphenylethane (6) is $1.540 \AA^{4 a}$ and that of phenyl-clamped 9,9'bifluorenyl (7) is $1.542 \AA .4 \mathrm{~b}$

The conformations of substituted ethanes have been studied for a long time to understand the role of substituents in control ling the relative stability of gauche and anti forms. ${ }^{5-9}$ In general, 1,1,2,2-tetraalkylethanes prefer the gauche conformation, ${ }^{8}$ whereas 1,1,2,2-tetraarylethanes, such as 1,1,2,2-tetraphenylthanes (e.g. 6), prefer the anti conformation. ${ }^{4 a}$ On the other hand, clamped aryl ethanes, the parent bianthrone (H-bia) and bifluorenyl (7), have been found to prefer the gauche conformation by dipole moment measurement ${ }^{7 a}$ and dynamic NMR

(3) (a) Kahr, B.; Van Engen, D.; Mislow, K.J . Am. Chem. Soc. 1986 108, 8305. (b) Flamm-ter Meer, M. A.; Beckhaus, H.-D.; Peters, K. von Schnering, H.-G.; Rüchardt, C. Chem. Ber. 1985, 118, 4665.

(4) (a) Dougherty, D. A.; Mislow, K.; Blount, J . F.; Wooten, J. B.; J acobus, J . J . Am. Chem. Soc. 1977, 99, 6149. (b) Dougherty, D. A.; Llort, F. M.; Mislow, K.; Blount, J. F. Tetrahedron 1978, 34, 1301.

(5) (a) Brownstein, S.; Dunogues, J .; Lindsay, D.; Ingold, K. U. J Am. Chem. Soc. 1977, 99, 2073. (b) Lunazzi, L.; Macciantelli, D.; Bernardi, F.; Ingold, K. U. J. Am. Chem. Soc. 1977, 99, 4573. (c) ElTorki, F. M.; Zens, A. P.; J acobus, J . J . Org. Chem. 1985, 50, 1313. (d) El-Torki, F. M.; J acobus, J . J . Org. Chem. 1985, 50, 1314.

(6) Olah, G. A.; Field, L. D.; Watkins, M. I.; Malhotra, R. J . Org. Chem. 1981, 46, 1761.

(7) (a) Huang, H. H. Aust. J . Chem. 1976, 29, 2415. (b) Huang, D.G.; Shukla, D.; Wan, P. J . Org. Chem. 1991, 56, 5437.

(8) Rüchardt, C.; Beckhaus, H. Angew. Chem., Int. Ed. Engl. 1980, 19, 429.

(9) Favini, G.; Simonetta, M.; Todeschini, R. J . Am. Chem. Soc. 1981 103, 3679.

10.1021/j0020196g CCC: $\$ 22.00$ @ 2002 American Chemical Society Published on Web 10/18/2002 


\section{SCHEME 1. Reduction Reactions of 9,10-Anthraquinones Mediated by Zinc Dust in the Presence of} Aqueous Ammonia

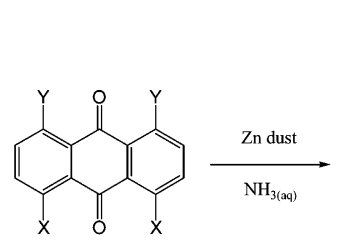

2a $(\mathrm{X}=\mathrm{Cl}, \mathrm{Y}=\mathrm{H})$

3a $(\mathrm{X}=\mathrm{OMe}, \mathrm{Y}=\mathrm{H})$

4a $(\mathrm{X}=\mathrm{H}, \mathrm{Y}=\mathrm{OH})$

5a $\left(\mathrm{X}=\mathrm{H}, \mathrm{Y}=\mathrm{NH}_{2}\right)$<smiles>O=C1c2ccccc2C(C2c3ccccc3C(=O)c3ccccc32)c2ccccc21</smiles>

9,9'-bianthracene-10,10'(9H,9'H)-dione (1, H-bia)
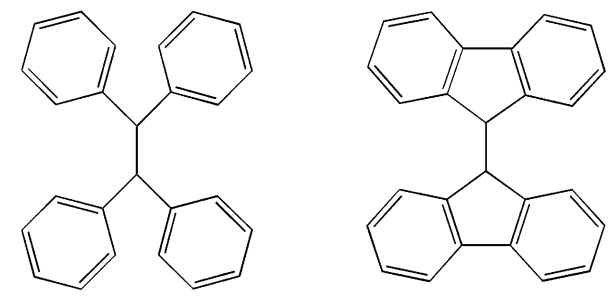

1,1,2,2-tetraphenylethane (6)

bifluorenyl (7)<smiles>[Y]c1ccc([Y])c(C(=O)c2c([Y])ccc([Y])c2C2c3c([Y])ccc([Y])c3C(=O)c3c([Y])ccc([Y])c32)c1</smiles>

2b $(\mathrm{X}=\mathrm{Cl}, \mathrm{Y}=\mathrm{H})$

2c $(\mathrm{X}=\mathrm{Cl}, \mathrm{Y}=\mathrm{H})$

2d $(\mathrm{X}=\mathrm{Cl}, \mathrm{Y}=\mathrm{H})$

3b $(\mathrm{X}=\mathrm{OMe}, \mathrm{Y}=\mathrm{H})$

4b $(\mathrm{X}=\mathrm{H}, \mathrm{Y}=\mathrm{OH})$

5b $\left(\mathrm{X}=\mathrm{H}, \mathrm{Y}=\mathrm{NH}_{2}\right)$

$4 c(X=H, Y=O H)$

5c $\left(\mathrm{X}=\mathrm{H}, \mathrm{Y}=\mathrm{NH}_{2}\right)$

4d $(\mathrm{X}=\mathrm{H}, \mathrm{Y}=\mathrm{OH})$

5d $\left(\mathrm{X}=\mathrm{H}, \mathrm{Y}=\mathrm{NH}_{2}\right)$
$\stackrel{\mathrm{Cl}}{\mathrm{C}} \stackrel{\mathrm{C}}{\mathrm{O}} \stackrel{\mathrm{O}}{\mathrm{H}} \stackrel{\mathrm{H}}{\mathrm{O}}$
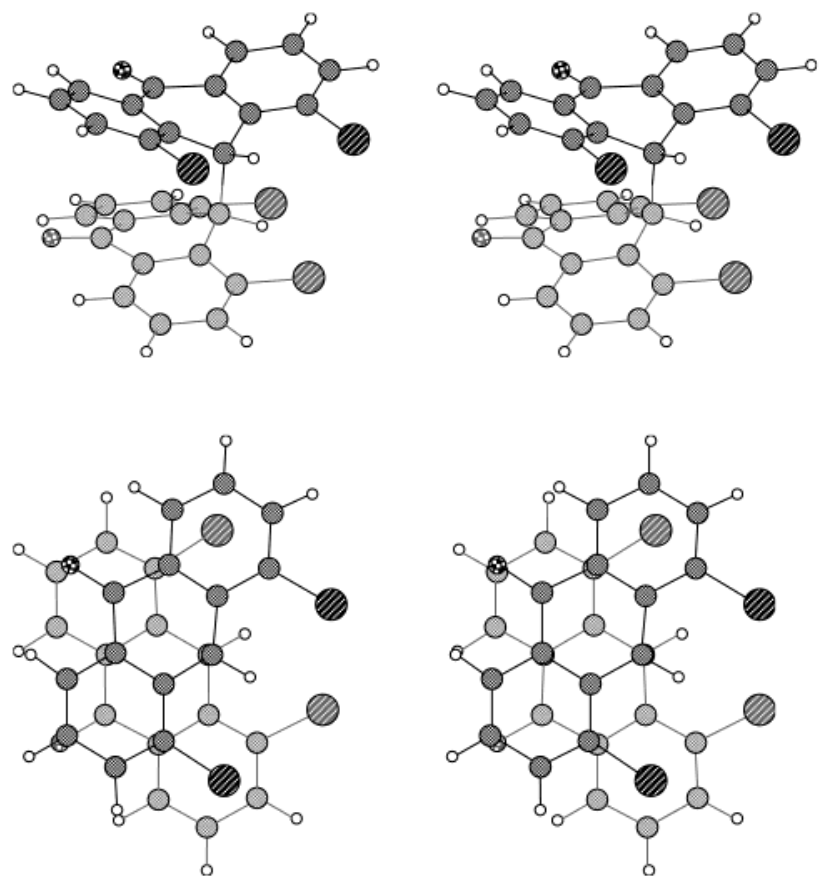

FIGURE 1. Stereoviews of the side view and top view of the X-ray structure of 1,1',8,8'-tetrachloro-9,9'-bianthracene-10,$10^{\prime}\left(9 \mathrm{H}, 9^{\prime} \mathrm{H}\right)$-dione (2b).

In this study, we aim to del ineate the reasons for the preferred conformation and the long $\mathrm{C}-\mathrm{C}$ bond length of bianthrones. For a structural element to be used in constructing supramolecular systems, it is important to learn how to control its conformation. Therefore, we have studied model compounds to shed light on the influence of the phenyl group and the functional group $Z$ in the central six-membered ring on the structure and relative stability of anti and gauche conformers (Figure 2).

\section{Experimental Section}

1,8-Dichloranthraquinone (2a) and 1,8-dihydroxyanthraquinone (4a) were purchased from a commercial source and $\mathbf{4 a}$ was recrystallized from benzene/hexane prior to use. 1,8apply to bianthrones. 


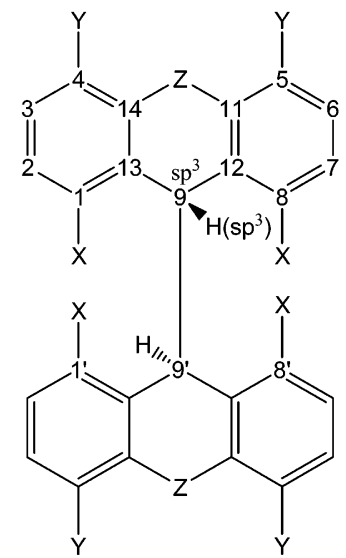

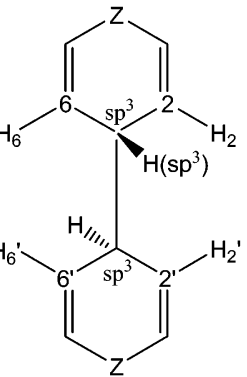

H-bia (1)

$$
\mathrm{X}=\mathrm{H} \quad \mathrm{Y}=\mathrm{H} \quad \mathrm{Z}=\mathrm{CO}
$$

model-1

$\mathrm{Z}=\mathrm{CO}$

Cl-bia (2b)

$$
\mathrm{X}=\mathrm{Cl} \quad \mathrm{Y}=\mathrm{H} \quad \mathrm{Z}=\mathrm{CO}
$$

model-2

$\mathrm{Z}=\mathrm{CH}_{2}$

OMe-bia (3b)

$\mathrm{X}=\mathrm{OMe} \quad \mathrm{Y}=\mathrm{H} \quad \mathrm{Z}=\mathrm{CO}$

model-3

$\mathrm{Z}=\mathrm{O}$

OH-bia (4b) $\quad \mathrm{X}=\mathrm{H} \quad \mathrm{Y}=\mathrm{OH} \quad \mathrm{Z}=\mathrm{CO}$

$\mathbf{N H}_{2}$-bia (5b) $\quad \mathrm{X}=\mathrm{H} \quad \mathrm{Y}=\mathrm{NH}_{2} \quad \mathrm{Z}=\mathrm{CO}$

Bianthrancene (8) $\mathrm{X}=\mathrm{H} \quad \mathrm{Y}=\mathrm{H} \quad \mathrm{Z}=\mathrm{CH}_{2}$

Bixanthene (9) $\quad \mathrm{X}=\mathrm{H} \quad \mathrm{Y}=\mathrm{H} \quad \mathrm{Z}=\mathrm{O}$

FIGURE 2. Structure of clamped ethanes and model compounds.

Dimethoxyanthraquinone (3a) and 1,8-diaminoanthraquinone (5a) were prepared according to literature procedures. ${ }^{10,11}$ Merck silica gel 60F sheets were used for analytical thin-layer chromatography and column chromatography was performed on Kieselgel 60 (230-400 mesh). Melting points were uncorrected. The ${ }^{1} \mathrm{H}$ and ${ }^{13} \mathrm{C}$ N MR spectra were obtained on Bruker spectrometers operating at frequencies as indicated for each compound. Chemical shifts are reported rel ative to $\mathrm{CDCl}_{3}\left(\delta_{\mathrm{H}}\right.$ 7.24) or to the residual protic solvent multiplet center at 2.05 ppm in acetone- $\mathrm{d}_{6}$ and at $77.0 \mathrm{ppm}$ in $\mathrm{CDCl}_{3}\left[\delta_{\mathrm{C}}\right.$ (central line of $\mathrm{t})$ ].

General Procedure for Preparation of Bianthrones by Reduction of 1,8-Disubstituted Anthraquinone Mediated with Zinc Dust/Aqueous Ammonia. 1,8-Disubstitued anthraquinone and zinc dust were suspended in $30 \%$ aqueous ammonia and heated for selected hours depending on the reactivities of anthraquinones. The reaction mixture was cool ed and then extracted with ethyl acetate (EtOAc) 4 times. The combined organic layers were dried over $\mathrm{MgSO}_{4}$ and concentrated. The residue was purified by column chromatography to afford bianthrones.

1,1',8,8-Tetrachloro-9,9'bianthracence-10,10 (9H,9' ' $^{\prime}$ dione (2b). Starting with 1,8-dichloroanthraquinone (207 mg, $0.75 \mathrm{mmol}$ ) and zinc dust (200 mg, $3.05 \mathrm{mmol}$ ) in 30\% aqueous ammonia $(10 \mathrm{~mL})$, the mixture was heated to $50{ }^{\circ} \mathrm{C}$ for $7 \mathrm{~h}$. Eluting with $\mathrm{CH}_{2} \mathrm{Cl}_{2} /$ hexane (1/4) and EtOAc/hexane (1/4) on silica gel gave $\mathbf{2} \mathbf{b}$ in $41 \%$ yield. I vory solid; $\mathrm{mp}>300^{\circ} \mathrm{C}$ dec; TLC (EtOAc/hexane (1:4)) $R_{f}$ 0.29; FTIR (KBr) 1673, 1588, $1302 \mathrm{~cm}^{-1}$; $1 \mathrm{H} \mathrm{NMR}\left(300 \mathrm{MHz} \mathrm{CDCl}_{3}\right) \delta 7.63$ (dd, J $=7.1 \mathrm{~Hz}$, $2.0 \mathrm{~Hz}, 4 \mathrm{H}), 7.37-7.32(\mathrm{~m}, 8 \mathrm{H}), 5.97(\mathrm{~s}, 2 \mathrm{H}) ;{ }^{13} \mathrm{C}$ NMR $(50$ $\left.\mathrm{MHz}_{2} \mathrm{CDCl}_{3}\right) \delta 180.5,152.8,136.6,136.0,132.8,129.3,124.9$, 43.3; FAB-MS m/z $523.0\left(\mathrm{M}^{+}+1\right)$; HRMS calcd for $\mathrm{C}_{28} \mathrm{H}_{14} \mathrm{O}_{2^{-}}$ ${ }^{35} \mathrm{Cl}_{4}\left(\mathrm{M}^{+}+1\right)$ 522.9748, found 522.9830. Anal. Calcd for $\mathrm{C}_{28} \mathrm{H}_{14} \mathrm{Cl}_{4} \mathrm{O}_{2}: \mathrm{C}, 64.15 ; \mathrm{H}, 2.69$. Found: $\mathrm{C}, 64.04 ; \mathrm{H}, 2.93$.

1,1',8,8-Tetramethoxy-9,9-bianthracence-10,10(9H,9H)dione (3b). Starting with 1,8-dimethoxyanthraquinone (296

(10) Birch, A. J .; Powell, V. H. Tetrahedron Lett. 1970, 3467.

(11) House, H. O.; Koepsell, D. G.; Campbell, W. J . J . Org. Chem 1972, 37, 1003 $\mathrm{mg}, 1.1 \mathrm{mmol}$ ) and zinc dust (576 $\mathrm{mg}, 8.8 \mathrm{mmol}$ ) in $30 \%$ aqueous ammonia $(20 \mathrm{~mL})$, the mixture was heated to $80^{\circ} \mathrm{C}$ for $20 \mathrm{~h}$. After purification by column chromatography el uting with EtOAc/hexane (3/7), $\mathbf{3 b}$ was isolated in $36 \%$ yield. White solid; mp 299-300 ${ }^{\circ} \mathrm{C}$ dec (lit. ${ }^{12} \mathrm{mp} 299-301{ }^{\circ} \mathrm{C}$ ); TLC (EtOACl hexane (1:1)) $R_{\mathrm{f}}$ 0.24; FTIR ( $\left.\mathrm{KBr}\right) 2939,2840,1668,1457,1267$ $\mathrm{cm}^{-1}$; ${ }^{1} \mathrm{H}$ NMR $\left(300 \mathrm{MHz} \mathrm{CDCl}_{3}\right) \delta 7.34(\mathrm{~d}, \mathrm{~J}=7.8 \mathrm{~Hz}, 4 \mathrm{H})$, $7.23(\mathrm{t}, \mathrm{J}=7.8 \mathrm{~Hz}, 4 \mathrm{H}), 6.80(\mathrm{~d}, J=7.8 \mathrm{~Hz}, 4 \mathrm{H}), 5.78(\mathrm{~s}, 2 \mathrm{H})$, $3.58(\mathrm{~s}, 12 \mathrm{H}) ;{ }^{13} \mathrm{C} \mathrm{NMR}\left(100 \mathrm{MHz} \mathrm{CDCl}_{3}\right) \delta 182.9,157.2,135.9$, 129.7, 127.9, 117.8, 112.4, 55.7, 37.1; FAB-MS m/z 507.2 $\left(\mathrm{M}+1^{+}\right)$; HRMS calcd for $\mathrm{C}_{32} \mathrm{H}_{26} \mathrm{O}_{6}\left(\mathrm{M}^{+}\right)$506.1729, found 506.1824. Anal. Calcd for $\mathrm{C}_{32} \mathrm{H}_{26} \mathrm{O}_{6}$ : C, 75.88; $\mathrm{H}, 5.17$. Found: C, 75.49; $H, 4.83$. (Note: a previous paper ${ }^{12}$ has erroneously assigned this compound to be 4,4',5,5'-tetramethoxy-9,9' bianthracence-10,10'(9H, $\left.9^{\prime} \mathrm{H}\right)$-dione.)

4,4'5,5'-Tetrahydroxy-9,9-bianthracence-10,10(9H,9H)dione (4b). Starting with 1,8-dihydroxyanthraquinone (500 $\mathrm{mg}, 2.80 \mathrm{mmol}$ ) and zinc dust (879 $\mathrm{mg}, 13.40 \mathrm{mmol})$ in $30 \%$ aqueous ammonia (50 $\mathrm{mL}$ ), the mixture was heated to reflux for $7 \mathrm{~h}$. After purification by column chromatography el uting with EtOAc/hexane (1/1), $\mathbf{4 b}$ was obtained in $18 \%$ yield. White solid; $\mathrm{mp} 210-213^{\circ} \mathrm{C}$ (lit. ${ }^{13} 230{ }^{\circ} \mathrm{C}$ ); TLC (EtOAC/hexane (1: 4)) $R_{f} 0.18$; FTIR (KBr) 3446, 1631, 1449, $1370 \mathrm{~cm}^{-1}$; ${ }^{1} \mathrm{H}$ NMR $\left(300 \mathrm{MHz} \mathrm{CDCl}_{3}\right) \delta 11.69(\mathrm{~s}, 4 \mathrm{H}), 7.36(\mathrm{t}, \mathrm{J}=7.7, \mathrm{~Hz}, 4 \mathrm{H})$, $6.88(\mathrm{~d}, \mathrm{~J}=7.7 \mathrm{~Hz}, 4 \mathrm{H}), 6.35(\mathrm{~d}, \mathrm{~J}=7.7 \mathrm{~Hz}, 4 \mathrm{H}), 4.56(\mathrm{~s}, 2 \mathrm{H})$; ${ }^{13} \mathrm{C}$ NMR $\left(100 \mathrm{MHz}_{2} \mathrm{CDCl}_{3}\right) \delta 192.2,161.9,141.0,135.6,119.5$ 117.1, 116.7, 56.2; FAB-MS m/z $451.1\left(\mathrm{M}^{+}+1\right)$; HRMS-FAB calcd for $\mathrm{C}_{28} \mathrm{H}_{18} \mathrm{O}_{6}\left(\mathrm{M}^{+}+1\right)$ 451.1103, found 451.1181. Anal. Calcd for $\mathrm{C}_{28} \mathrm{H}_{18} \mathrm{O}_{6}$ : C, 74.66; $\mathrm{H}, 4.03$. Found: C, 74.46; $\mathrm{H}$, 3.94.

4,4',5,5'-Tetraamino-9,9'-bianthracence-10,10 (9H,9H)dione (5b). Starting with 1,8-diaminoanthraquinone (209 mg, $0.88 \mathrm{mmol}$ ) and zinc dust ( $231 \mathrm{mg}, 3.53 \mathrm{mmol}$ ) in $30 \%$ aqueous ammonia (10 mL), the mixture was brought to reflux for $6 \mathrm{~h}$. After purification by column chromatography eluting with gradients of EtOAc/hexane (1/1 to 9/1), 5 b was isolated in $71 \%$ yield. Dark green solid; mp $185-190{ }^{\circ} \mathrm{C} \mathrm{dec}$; TLC $\left(\mathrm{CH}_{2} \mathrm{Cl}_{2}\right) \mathrm{R}_{\mathrm{f}}$ 0.1; FTIR (K Br) 3473, 3449, 3357, 3327, 1622, 1608, $1249 \mathrm{~cm}^{-1}$; ${ }^{1} \mathrm{H}$ NMR $\left(300 \mathrm{MHz}\right.$, acetone- $\left.\mathrm{d}_{6}\right) \delta 6.99$ (t, J $\left.=8.1 \mathrm{~Hz}, 4 \mathrm{H}\right), 6.82$ (br s, 8H), $6.59(\mathrm{dd}, \mathrm{J}=8.1,0.7 \mathrm{~Hz}, 4 \mathrm{H}), 6.07(\mathrm{~d}, \mathrm{~J}=8.1 \mathrm{~Hz}$, $4 \mathrm{H}), 4.31(\mathrm{~s}, 2 \mathrm{H}) ;{ }^{13} \mathrm{C}$ NMR $\left(75 \mathrm{MHz} \mathrm{CDCl}_{3}\right) \delta 189.9,151.3$, 142.5.0, 132.8, 117.7, 116.9, 116.3, 58.8; FAB-MS m/z 447.2 $\left(\mathrm{M}^{+}+1\right) \mathrm{HRMS}$ calcd for $\mathrm{C}_{28} \mathrm{H}_{22} \mathrm{O}_{2} \mathrm{~N}_{4}\left(\mathrm{M}^{+}+1\right) 447.1821$, found 447.1834. We were unable to obtain accurate elemental analysis results due to the instability of this compound in the air.

Bianthracene (8). Compound 8 was isolated in $41 \%$ yield by reduction of anthrone ( $500 \mathrm{mg}, 2.58 \mathrm{mmol}$ ) with zinc dust (300 mg, $1.55 \mathrm{mmol}$ ) in glacial acetic acid ( $5 \mathrm{~mL}$ ) according to the known procedure. White platelets; $\mathrm{TLC}\left(\mathrm{CH}_{2} \mathrm{Cl}_{2}\right.$ /hexane (1:4)) $\mathrm{R}_{\mathrm{f}}$ 0.52; FTIR (KBr) 3022, 2909, $1479 \mathrm{~cm}^{-1}$; ${ }^{1 \mathrm{H}}$ NMR (400 $\left.\mathrm{MHz}_{2} \mathrm{CDCl}_{3}\right) \delta 2.36(\mathrm{~d}, \mathrm{~J}=18.85 \mathrm{~Hz}, 2 \mathrm{H}), 3.32(\mathrm{~d}, \mathrm{~J}=18.85$ $\mathrm{Hz}, 2 \mathrm{H}), 4.38(\mathrm{~s}, 2 \mathrm{H}), 6.76(\mathrm{~d}, \mathrm{~J}=7.47 \mathrm{~Hz}, 4 \mathrm{H}), 7.02-7.04(\mathrm{~m}$, $8 \mathrm{H}), 7.12-7.16(\mathrm{~m}, 4 \mathrm{H}) ;{ }^{13} \mathrm{C}$ NMR $\left(100 \mathrm{MHz}, \mathrm{CDCl}_{3}\right) \delta 34.67$ 55.87, 125.59, 126.36, 127.22, 129.03, 136.80, 138.06.

Bixanthene (9). Compound 9 was isolated in $10 \%$ yiel d by dimerization of xanthene $(2.4 \mathrm{~g}, 0.013 \mathrm{~mol})$ promoted by ditert-butyl-peroxide ( $2 \mathrm{~mL}$ ) according to the known procedure. White platelets; TLC $\left(\mathrm{CH}_{2} \mathrm{Cl}_{2} /\right.$ hexane (1:4)) $\mathrm{R}_{\mathrm{f}} 0.54$; FTIR (KBr) 1447, $1261 \mathrm{~cm}^{-1}$; ${ }^{1} \mathrm{H}$ NMR $\left(400 \mathrm{MHz} \mathrm{CDCl}_{3}\right) \delta 7.18$ (td, J = $7.63 \mathrm{~Hz}, 1.49 \mathrm{~Hz}, 4 \mathrm{H}), 6.91$ (td, J $=7.63 \mathrm{~Hz}, 1.49 \mathrm{~Hz}, 4 \mathrm{H})$, $6.85(\mathrm{~d}, \mathrm{~J}=7.63 \mathrm{~Hz}, 4 \mathrm{H}), 6.64(\mathrm{dd}, \mathrm{J}=7.63 \mathrm{~Hz}, 1.49 \mathrm{~Hz}, 4 \mathrm{H})$, $4.18(\mathrm{~s}, 2 \mathrm{H}) ;{ }^{13} \mathrm{C}$ NMR $\left(100 \mathrm{MHz}, \mathrm{CDCl}_{3}\right) \delta 153.0,129.1,128.1$, 122.6, 121.8, 115.8, 49.5 .

X-ray Analysis. Colorless, almost transparent crystals were grown by slow vapor diffusion of a nonsoluble solvent into either a saturated chloroform or a benzene solution of bianthrone derivatives $\mathbf{2 b}-\mathbf{4 b} \mathbf{b}, \mathbf{8}$, and $\mathbf{9}$. Compound $\mathbf{5 b}$ (light green

(12) Shyamasundar, N.; Caluwe, P. J . Org. Chem. 1981, 46, 1552.

(13) Geiger, W. Chem. Ber. 1974, 107, 2976. 
color) is extremely air-sensitive and hard to dissolve in either chloroform or benzene, and thus crystals were grown by slow vapor diffusion of hexane into an ethyl acetate solution of $\mathbf{5 b}$ under nitrogen gas atmosphere and handled with special care. Suitable single crystals were sel ected under a microscope and mounted on a glass fiber. All measurements were made on a SMART CCD diffractometer, using Mo $K \alpha$ radiation $(\lambda=$ $0.7107 \AA$ ) at $100 \mathrm{~K}$ for $\mathbf{2 b}$ and $150 \mathrm{~K}$ for $\mathbf{3 b}-\mathbf{5 b}$ as well as $\mathbf{8}$ and 9 with a liquid nitrogen device. The data were collected using the $\omega$-step scan technique. The cell parameters were determined using all the valid reflections. The intensity data were corrected for Lorentz and polarization effects, and refinement was performed using the empirical absorption correction based on the equivalent reflections.

The structures were solved using direct methods and difference Fourier techniques and refined by least-squares analysis. The non-hydrogen atoms were refined anisotopically, and the hydrogen atoms were included in an idealized geometry but not refined. All calculations were carried out using the SHE LX program. The detailed data collection, refinement parameters, and bond lengths and angles, as well as ORTEP drawings, of $\mathbf{2 b}-\mathbf{5 b}, \mathbf{8}$, and $\mathbf{9}$ are given as Supporting Information.

Computational Details. Bianthrones were used to test the suitability of semiempirical $\left(\mathrm{AM}^{14}\right.$ and $\left.\mathrm{PM} 3^{15}\right)$ and $\mathrm{DF} \mathrm{T}^{16}$ calculations. The gas-phase calculated results at the B3LYP/ 6-31G* 17 level were better than that of AM 1 and PM3; the wrong conformation (anti) was predicted to be the most stable by semiempirical methods and the cal culated central $\mathrm{C}\left(\mathrm{sp}^{3}\right)-$ $\mathrm{C}\left(\mathrm{sp}^{3}\right)$ bond lengths were shorter than that in the X-ray structures by 0.04 to $0.06 \AA$. Therefore, all gas-phase calculations presented were carried out at the B3LYP/6-31G* level using Gaussian 98. ${ }^{18 a}$ Frequency analysis was carried out to characterize whether the stationary point was a local minimum or maximum. Initial conformation of the hydroxy, methoxy, and amino groups of OMe-bia (3b), OH-bia (4b), and $\mathbf{N H}_{\mathbf{2}}$-bia (5b) were taken from the X-ray structures. Single-point SCRF solution-phase calculations, whose geometries were taken from the Gaussian 98 gas-phase final geometries, were carried out at the B 3LYP/6-31G* level with fine grid (keywords gdftmed, gdftfine, and gdftgrad $=-13$ ) and chlor oform as solvent (4.8 for dielectric constant, and 2.517 $\AA$ for probe radius) using J aguar Version 3.5. ${ }^{18 \mathrm{~b}-\mathrm{e}}$

(14) (a) Dewar, M. J . S.; Thiel, W. J . Am. Chem. Soc. 1977, 99, 4499. (b) Dewar, M. J. S.; McKee, M. L.; Rzepa, H. S. J . Am. Chem. Soc. 1978, 100, 3607. (c) Dewar, M. J. S.; Zoebisch, E. G.; Healy, E. F. J Am. Chem. Soc. 1985, 107, 3902. (d) Dewar, M. J . S.; Reynolds, X. H. J . Comput. Chem. 1986, 2, 140.

(15) (a) Stewart, J. J. P. J . Comput. Chem. 1989, 10, 209. (b) Stewart, J . J . P. J. Comput. Chem. 1989, 10, 221.

(16) (a) Hobenberg, P.; Kohn, W. Phys. Rev. 1964, 136, B864. (b) Kohn, W.; Sham, L. J. Phys. Rev. 1965, 140, A1133.

(17) (a) Becke, A. D. J . Chem. Phys. 1993, 98, 5648. (b) Lee, C.; Yang, W.; Parr, R. G. Phys. Rev. B 1988, 37, 785. (c) Miehlich, B.; Savin, A.; Stoll, H.; Preuss, H. Chem. Phys. Lett. 1989, 157, 200.

(18) (a) Frisch, M. J .; Trucks, G. W.; Schlegel, H. B.; Scuseria, G. E.; Robb, M. A.; Cheeseman, J . R.; Zakrzewski, V. G.; Montgomery, J . A.; Stratmann, R. E.; Burant, J. C.; Dapprich, S.; Millam, J. M. Daniels, A. D.; Kudin, K. N.: Strain, M. C.; Farkas, O.; Tomasi, J.; Barone, V.; Cossi, M.; Cammi, R.; Mennucci, B.; Pomelli, C.; Adamo, C.; Clifford, S.; Ochterski, J .; Petersson, G. A.; Ayala, P. Y.; M orokuma, Q.; Cui, K.; Malick, D. K.; Rabuck, A. D.; Raghavachari, K.; Foresman, J. B.; Cioslowski, J .; Ortiz, J . V.; Stefanov, B. B.; Liashenko, G.; Liu A.; Piskorz, P.; Komaromi, I.; Gomperts, R.; Martin, R. L.; Fox, D. J .; Keith, T.; Al-Laham, M. A.; Peng, C. Y.; Nanayakkara, A.; Gonzalez, C.; Challacombe, M.; Gill, P. M. W.; J ohnson, B.; Chen, W.; Wong, M. W.; Andres, J . L.; Gonzalez, C. M.; Gordon, M. S.; Replogle, E. S.; Pople, J. A. Gaussian 98, Revision A.5; Gaussian, Inc.: Pittsburgh, PA, 1998. (b) J aguar 3.5; Schrödinger, Inc.: Portland, OR, 1998. (c) Tannor, D J.; Marten, B.; Murphy, R. B.; Friesner, R. A.; Sitkoff, D.; Nicholls, A.; Ringnalda, M. N.; Goddard, W. A., III; Honig, B. J . Am. Chem. Soc 1994, 116, 11875. (d) Marten, B.; Kim, K.; Cortis, C.; Friesner, R. A.; Murphy, R. B.; Ringnalda, M. N.; Sitkoff, D.; Honig, B.J . Phys. Chem. 1996, 100, 11775. (e) CRC Handbook of Chemistry and Physics, 79th ed.; Lide, D. R. Ed.; CRC Press: Boca Raton, FL, 1998.

\section{Results and Discussion}

Bianthrones $\mathbf{2} \mathbf{b}-\mathbf{5} \mathbf{b}$ were synthesized by reduction of 1,8-disubstituted 9,10-anthraquinones using zinc dust in aqueous ammonia. Scheme 1 outlines the reactions and products. 8 and $\mathbf{9}$ were prepared according to the previously published procedures. ${ }^{19}$ The mass spectra of $\mathbf{C l}$ bia (2b) and OMe-bia (3b) showed very intense signals at $\mathrm{m} / \mathrm{z} 524$ and 507, respectively, corresponding to their molecular ion peaks, whereas the mass spectra of $\mathbf{O H}$ bia (4b) and $\mathbf{N H}_{2}$-bia (5b) displayed very weak molecular ion peaks at $m / z 451$ and $447\left(M^{+}+1\right)$ and prominent fragments at $\mathrm{m} / \mathrm{z} 225$ and 223 , respectively. In the ${ }^{1} \mathrm{H}$ NMR spectra, a sharp singlet with 2-proton counts, appearing at $\delta 5.97$ for $\mathbf{2} \mathbf{b}$ and $\delta 5.78$ for $\mathbf{3 b}$, was attributed to the methine protons $\left(\mathrm{H}-9\right.$ and $\left.\mathrm{H}-9^{\prime}\right)$. However, the methine protons in $\mathbf{4} \mathbf{b}$ and $\mathbf{5 b}$ occurred at relatively higher fields of $\delta 4.56$ and 4.31 . The structures of bianthrones studied in this paper were unambiguously determined by X-ray diffraction analyses at $150 \mathrm{~K}$ and the carbonyl groups all existed as keto forms in the solid state. For OMe-bia (3b) grown in $\mathrm{CHCl}_{3} /$ pentane, there were two molecules observed per asymmetric unit and the two were enantiomers. The qual ity of its crystal was not good enough probably due to the twining. Although the magnitude of bond lengths and angles was not $100 \%$ accurate due to the relatively poor resolution $(R=0.105)$ of this structure, the conformation observed should not be far from the correct one.

The gauche conformation had been found for all compounds, except for $\mathbf{N H}_{\mathbf{2}}$-bia. Under different solvent conditions for crystallization, only OMe-bia afforded the structure of both gauche and anti conformation. The structural details of our X-ray structures and that of parent bianthrone found in the literature $\mathrm{e}^{20}$ are shown in Table 1. The nonplanarity of 10-substituted anthracen9-ones has been discussed by Rabideau and co-workers. ${ }^{21}$ They found that the parent anthracen-9-one is planar, but the size of the 10-substituent influences the nonplanarity of the central ring. Hence, it is not surprising to find that theX-ray structures showed nonplanarity of the central rings of bianthrones (e.g., see stereoviews in Figure 1.) The degree of nonplanarity of the anthracenone moiety is measured by a "flipping angle", which is the average of absolute values of dihedral angles $\mathrm{C}(11)-$ $C(12)-C(9)-C(13), C(14)-C(13)-C(9)-C(12)$, and the two corresponding dihedral angles of the other anthracenone unit. (See Figure 2 for atom labels.) A $0^{\circ}$ flipping angle means the anthracenone unit is planar. When the flipping angle is larger than $0^{\circ}$, the central six-membered ring of the anthracenone unit is in a boat form, with the $\mathrm{C}\left(\mathrm{sp}^{3}\right)$ and $\mathrm{C}(=\mathrm{O})$ carbons being the two tips of the boat (Figure $3 b)$. Due to the boat conformation of the central ring, the two flanking phenyl groups are pointing to the direction opposite to the tips of the boat, making a facestacked relationship of upper and lower decks possible. For example, when the central $\mathrm{C}\left(\mathrm{sp}^{3}\right)$ and carbonyl group

(19) (a) Berke, C. M.; Streitwieser, A., J r.J . Organomet. Chem. 1980, 197, 123. (b) Bell, F.; Waring, D. H. J . Chem. Soc. 1949, 267. (c) Badejo I. T.; Karaman, R.; Pinkerton, A. A.; Fry, J . L. J . Org. Chem. 1990 55, 4327. (d) Schönberg, A.; Rosenbach, A.; Krüll, H.; Ostwald, U. Chem. Ber. 1925, 58, 8B, 1793; Chem. Abstr. 1926, 20, 364.

(20) Ehrenberg, M. Acta Crystallogr. 1967, 22, 482.

(21) Sygula, A.; Sygula, R.; Fronczek, F. R.; Rabideau, P. W. J . Org. Chem. 1992, 57, 3286. 
TABLE 1. Geometry of Bianthrones in X-ray Structures

\begin{tabular}{|c|c|c|c|c|c|}
\hline conformer & $\begin{array}{c}\mathrm{C}\left(\mathrm{sp}^{3}\right)-\mathrm{C}\left(\mathrm{sp}^{3}\right) \\
(\AA)\end{array}$ & $\begin{array}{l}\text { dihedral } \\
\text { angle } \\
\text { (deg) }\end{array}$ & $\begin{array}{l}\text { flipping } \\
\text { angle } \\
\text { (deg) }\end{array}$ & $\begin{array}{c}\theta^{\mathrm{c}} \\
\text { (deg) }\end{array}$ & $\begin{array}{c}\pi-\pi^{d} \\
(\AA)\end{array}$ \\
\hline \multicolumn{6}{|c|}{ gauche } \\
\hline H-bia (1) & 1.600 & 72.8 & 19.1 & 115.1 & 2.355 \\
\hline Cl-bia (2b) $)^{f}$ & 1.619 & 66.6 & 35.5 & 111.2 & 3.217 \\
\hline OMe-bia (3b) fi,g & 1.64 & 61 & 30 & 112 & 3.00 \\
\hline OH-bia $(\mathbf{4 b})^{h}$ & 1.603 & 63.4 & 19.2 & 114.9 & 2.364 \\
\hline \multicolumn{6}{|c|}{ anti } \\
\hline OMe-bia $(3 \mathbf{b})^{\mathrm{h}}$ & 1.604 & 180.0 & 36.2 & 110.7 & 3.191 \\
\hline $\mathbf{N H}_{\mathbf{2}}$-bia (5b) & 1.611 & 167.5 & 37.9 & 112.1 & 3.157 \\
\hline
\end{tabular}

a Absolute value of $\mathrm{H}-\mathrm{C}\left(\mathrm{sp}^{3}\right)-\mathrm{C}\left(\mathrm{sp}^{3}\right)-\mathrm{H} .{ }^{\mathrm{b}}$ Average of absolute values of dihedral angles $C(11)-C(12)-C(9)-C(13), C(14)-C(13)-$ $\mathrm{C}(9)-\mathrm{C}(12)$, and the two corresponding dihedral angles of the other anthracenone unit; flipping angle scored the degree of nonplanarity of the anthracenone moiety. ${ }^{\mathrm{C}}$ Average of $\mathrm{C}(12)-\mathrm{C}(9)-\mathrm{C}(13)$ and $C\left(12^{\prime}\right)-C\left(9^{\prime}\right)-C\left(13^{\prime}\right)$. ${ }^{d}$ Defined as the distance between midpoints of $C(1) \cdots C(8)$ and $C\left(1^{\prime}\right) \cdots C\left(8^{\prime}\right) .{ }^{e}$ Geometry from ref $20 .{ }^{f}$ Solvent for crystallization was a $\mathrm{CHCl}_{3} /$ pentane mixture. 9 The uncertainty of the geometric parameters is larger by an order of magnitude than those of other structures. ${ }^{\mathrm{h}}$ Solvent for crystallization was a benzene/hexane mixture. i Solvent for crystallization was a EtOAd hexane mixture.

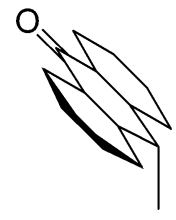

a

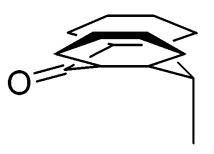

b
FIGURE 3. (a) Planar anthracenone unit. (b) Anthracenone unit with a nonzero flipping angle.

are pointing downward, the flanking phenyl groups are flipped upward (Figure 3b). Along with the change in the flipping angle, the intraring angles of the boat and the $\pi-\pi$ distance between the anthracenone units are affected. We chose the average of the $\mathrm{C}(12)-\mathrm{C}(9)-\mathrm{C}(13)$ and $\mathrm{C}\left(12^{\prime}\right)-\mathrm{C}\left(9^{\prime}\right)-\mathrm{C}\left(13^{\prime}\right)$ angles $(\theta)$ to represent the change in intraring angles and defined a so-called " $\pi-\pi$ distance" as the distance between the midpoints of $\mathrm{C}(1) \cdots \mathrm{C}(8)$ and $\mathrm{C}\left(1^{\prime}\right) \cdots \mathrm{C}\left(8^{\prime}\right)$. This " $\pi-\pi$ distance" is a good measure of structural deformation around the $\mathrm{C}\left(\mathrm{sp}^{3}\right)-$ $\mathrm{C}\left(\mathrm{sp}^{3}\right)$ bond; both a long $\mathrm{C}\left(\mathrm{sp}^{3}\right)-\mathrm{C}\left(\mathrm{sp}^{3}\right)$ bond length and a large flipping angle of the anthracenone unit will result in a large " $\pi-\pi$ distance".

The above structural features of crystal structures of bianthrones are summarized in Table 1 . The $\mathrm{C}\left(\mathrm{sp}^{3}\right)-$ $\mathrm{C}\left(\mathrm{sp}^{3}\right)$ bond lengths in the $\mathrm{X}$-ray structures of bianthrones are no less than $1.60 \AA$ (Table 1 ). In examination of all four gauche structures, we found the bond lengths of 1,1',8,8'-tetrasubstituted bianthrones (CI-bia, OMe-bia) are longer than that of parent (H-bia) or 4,4',5,5'tetrasubstituted bianthrones (OH-bia). The flipping angle, $\theta$, and $\pi-\pi$ distance of gauche conformers can also be grouped according to the positions of substituents. When $1,1^{\prime}, 8,8^{\prime}$ positions are substituted, the degree of nonplanarity is larger (see flipping angles), the intraring angle $(\theta)$ is smaller, and the $\pi-\pi$ distance is larger than the corresponding values of the less sterically hindered parent or $4,4^{\prime}, 5,5^{\prime}$-substituted analogues. ${ }^{22}$ On the other hand, the position of substituents does not make such distinct differences for flipping angle, intraring angle, or $\pi-\pi$ distance between anti conformers of $\mathbf{N H}_{\mathbf{2}}$-bia and OMe-bia. One interesting observation in the $\mathbf{C l - b i a}$ structure is that the closest pair of $\mathrm{Cl}$ atoms has a distance of $3.509 \AA$ (the van der Waals radius of the $\mathrm{Cl}$ atom is $1.80 \AA$ ), which is within the range of intermolecular $\mathrm{Cl} \cdots \mathrm{Cl}$ distances found in the Cambridge Structure Database (3.2 to 3.6 ). Desiraju proposed that these $\mathrm{Cl} \cdots \mathrm{Cl}$ interactions are of attractive nature. ${ }^{23}$

Theoretical data summarized in Table 2 show that structural features such as long $\mathrm{C}\left(\mathrm{sp}^{3}\right)-\mathrm{C}\left(\mathrm{sp}^{3}\right)$ bonds, nonplanarity of the anthracenone moiety, and structural differences in the gauche form of $4,4^{\prime}, 5,5^{\prime}$ - and $1,1^{\prime}, 8,8^{\prime}$ tetrasubstituted bianthrones found in the X-ray structures are preserved in calculated gas-phase results of bianthrones $(\mathbf{1}, \mathbf{2} \mathbf{b}-\mathbf{5 b})$ at the theory level of B $3 L Y P / 6$ 31G*. The calculated values of the $\mathrm{C}\left(\mathrm{sp}^{3}\right)-\mathrm{C}\left(\mathrm{sp}^{3}\right)$ bond length, $\mathrm{H}-\mathrm{C}\left(\mathrm{sp}^{3}\right)-\mathrm{C}\left(\mathrm{sp}^{3}\right)-\mathrm{H}$ dihedral angle, flipping angle, intraring angle, and $\pi-\pi$ distance deviate from the observed by no more than $0.022 \AA, 12.5^{\circ}, 5.3^{\circ}, 1.7^{\circ}$, and $0.290 \AA$, respectively. While the calculated and observed geometric parameters resemble each other for some conformers, the noticeable deviation of the observed $\mathrm{H}-\mathrm{C}\left(\mathrm{sp}^{3}\right)-\mathrm{C}\left(\mathrm{sp}^{3}\right)-\mathrm{H}$ angle of $\mathbf{N H}_{\mathbf{2}}$-bia (167.5 ${ }^{\circ}$, see Table 1 ) from the ideal anti conformation $\left(180^{\circ}\right)$ is an indication of the presence and importance of crystal packing forces. ${ }^{24}$ For all bianthrones, the gauche conformation is calculated to be more stable than the anti in the gas phase (see $\Delta \mathrm{E}$ in Table 2 ). When a continuum solvation model for chloroform is applied in calculation, the gas-phase gauche preference is either enhanced or reduced (see $\Delta \mathrm{E}_{\mathrm{CHCl}_{3}}$ in Table 2). However, only $\mathbf{N H}_{\mathbf{2}}$-bia, which has a small gas-phase gauche preference ( $\Delta \mathrm{E}$ (anti-gauche) $=0.46 \mathrm{kcal} / \mathrm{mol}$ ), showed a reversed (anti) structural preference $\left(\Delta \mathrm{E}_{\mathrm{CHCl}_{3}}(\right.$ anti-gauche $\left.)=-0.17 \mathrm{kcal} / \mathrm{mol}\right)$ in solution. Experimentally, crystal structures are in the gauche conformation for $\mathbf{C l - b i a , ~ O M e - b i a , ~ a n d ~} \mathbf{O H}-\mathbf{b i a}$, but not for $\mathbf{N H}_{\mathbf{2}}$-bia. Therefore, the theoretical results correspond well to the experimental findings. Among the bianthrones (2b-5b), OMe-bia is unique in that solvent molecules are present in the crystal structures. For the gauche structure obtained in crystals grown in a $\mathrm{CHCl}_{3} /$ pentane mixture, chloroform molecules are present; for the anti structure obtained in crystals grown in a benzene/hexane mixture, benzene molecules are present. Since the calculated gas-phase anti-gauche energy difference of OMe-bia is small, $0.65 \mathrm{kcal} / \mathrm{mol}$, it should be easy for the packing force between benzene and OMebia molecules to override the gauche preference. ${ }^{25}$

(22) Although the gauche structure of OMe-bia is not as accurately determined as other structures, the structural differences between $1,1^{\prime}, 8,8^{\prime}$ - and $4,4^{\prime}, 5,5^{\prime}$-tetrasubstituted bianthrones are also observed in the calculated structures.

(23) Sarma, J . A.; Desiraju, G. R. Acc. Chem. Res. 1986, 19, 222.

(24) In $\mathbf{N H}_{\mathbf{2}}$-bia crystal, there are plenty of hydrogen bond donors and acceptors. One would assume some of the packing forces come from hydrogen bonding. However, as the 4,4',5,5'-amino groups form intramolecular hydrogen bonds with the nearby carbonyl groups readily, no normal intermolecular hydrogen bond was observed in the crystal structure. The two closest intermolecular contacts, 2.41 and $2.45 \AA$, are between $(\mathrm{C}=) \mathrm{O} \cdots \mathrm{H}(-\mathrm{N})$ and between $(\mathrm{N}-) \mathrm{H} \cdots \mathrm{N}$, respectively. The functional groups are not coplanar to each other, e.g., the amino group is above the carbonyl group (or another amino group). Although each molecule has two carbonyl groups, only one is involved in such contact, which correlates well with the observed asymmetric feature of the anti conformation of $\mathbf{N H}_{\mathbf{2}}$-bia. 
TABLE 2. Geometry and Energy Calculated at the B3LYP/6-31G* Level

\begin{tabular}{|c|c|c|c|c|c|c|c|}
\hline conformer & $\begin{array}{c}C\left(\mathrm{sp}^{3}\right)-\mathrm{C}\left(\mathrm{sp}^{3}\right) \\
(\AA)\end{array}$ & $\begin{array}{c}\text { dihedral angle } \\
\text { (deg) }\end{array}$ & $\begin{array}{c}\text { flipping angle } \\
\text { (deg) }\end{array}$ & $\begin{array}{c}\theta \\
\text { (deg) }\end{array}$ & $\begin{array}{c}\pi-\pi \\
(\AA)\end{array}$ & $\begin{array}{c}\Delta \mathrm{E} \\
(\mathrm{kcal} / \mathrm{mol})\end{array}$ & $\begin{array}{c}\Delta \mathrm{E}_{\mathrm{CHCl}_{3}} \\
(\mathrm{kcal} / \mathrm{mol})\end{array}$ \\
\hline \multicolumn{8}{|l|}{ H-bia (1) } \\
\hline 0 & 1.666 & 0.0 & $33.2(8.5)$ & 111.0 & & 12.05 & \\
\hline 60 & 1.619 & 70.5 & 23.1(5.8) & 113.4 & 2.642 & 0.00 & 0.00 \\
\hline 120 & 1.647 & 126.0 & $30.6(8.1)$ & 112.0 & & 5.25 & \\
\hline 180 & 1.621 & 180.0 & $35.3(9.2)$ & 111.1 & 3.188 & 1.92 & 2.58 \\
\hline \multicolumn{8}{|l|}{ Cl-bia (2b) } \\
\hline 60 & 1.634 & 59.7 & $37.0(10.0)$ & 110.9 & 3.339 & 0.00 & 0.00 \\
\hline 180 & 1.623 & 180.0 & $40.5(11.1)$ & 109.8 & 3.515 & 2.86 & 2.59 \\
\hline \multicolumn{8}{|l|}{ OMe-bia (3b) } \\
\hline 60 & 1.632 & 62.9 & 31.0(8.6) & 111.6 & 3.058 & 0.00 & 0.00 \\
\hline 180 & 1.626 & 179.9 & 36.1(10.3) & 110.3 & 3.300 & 0.65 & 2.50 \\
\hline \multicolumn{8}{|l|}{ OH-bia (4b) } \\
\hline 60 & 1.624 & 72.0 & $24.6(4.2)$ & 114.0 & 2.654 & 0.00 & 0.00 \\
\hline 180 & 1.631 & 180.0 & $36.7(6.1)$ & 111.6 & 3.195 & 2.27 & 2.81 \\
\hline \multicolumn{8}{|l|}{$\mathrm{NH}_{2}$-bia (5b) } \\
\hline 60 & 1.623 & 72.3 & $26.8(4.9)$ & 113.8 & 2.759 & 0.00 & 0.00 \\
\hline 180 & 1.623 & 180.0 & $38.7(7.0)$ & 111.3 & 3.283 & 0.46 & -0.17 \\
\hline \multicolumn{8}{|l|}{ model-1 } \\
\hline 0 & 1.627 & 0.0 & $3.9(1.7)$ & 112.3 & & 9.09 & \\
\hline 60 & 1.581 & 66.6 & $1.0(0.2)$ & 113.4 & & 0.00 & \\
\hline 120 & 1.606 & 123.9 & $0.8(1.7)$ & 113.1 & & 4.57 & \\
\hline 180 & 1.603 & 180.0 & $7.4(2.1)$ & 112.5 & & 2.13 & \\
\hline \multicolumn{8}{|l|}{ model-2 } \\
\hline 0 & 1.622 & 0.0 & $8.0(4.0)$ & 110.9 & & 8.22 & \\
\hline 60 & 1.576 & 65.8 & $0.4(0.8)$ & 111.9 & & 0.00 & \\
\hline 120 & 1.600 & 121.9 & $1.9(0.5)$ & 111.6 & & 4.25 & \\
\hline 180 & 1.590 & 180.0 & $10.5(3.8)$ & 111.2 & & 1.31 & \\
\hline \multicolumn{8}{|l|}{ model-3 } \\
\hline 0 & 1.619 & 0.0 & $8.6(2.8)$ & 107.5 & & 6.97 & \\
\hline 60 & 1.578 & 64.5 & $2.8(0.2)$ & 108.5 & & 0.00 & \\
\hline 120 & 1.601 & 121.1 & $4.3(0.9)$ & 108.1 & & 3.77 & \\
\hline 180 & 1.582 & 180.0 & $9.6(2.8)$ & 107.9 & & 0.67 & \\
\hline \multicolumn{8}{|c|}{ bianthracene (8) } \\
\hline 60 & 1.599 & 62.9 & $30.4(16.0)$ & 111.6 & 3.049 & 0.00 & 0.00 \\
\hline \multirow{2}{*}{\multicolumn{8}{|c|}{ bixanthene (9) }} \\
\hline & & & & & & & \\
\hline 60 & 1.600 & 65.6 & 24.1(9.1) & 110.0 & 2.817 & 0.00 & 0.00 \\
\hline 180 & 1.603 & 180.0 & 34.9(14.3) & 108.3 & 3.286 & 0.40 & 0.95 \\
\hline
\end{tabular}

a Average of absolute values of flipping angles. Values in parentheses are the average of absolute values of dihedral angles $C(12)-$ $C(13)-C(14)-Z$ and $C(13)-C(12)-C(11)-Z$ (see Figure 2). These dihedral angles score the degree of nonplanarity of $Z ; Z$ stands for the atom within the six-membered ring. That is, the oxygen atom of the carbonyl group for Model-1 and $\mathbf{H}$-bia is not considered. For Model1, Model-2, and Model-3, dihedral angles corresponding to $C(12)-C(13)-C(14)-Z$ and $C(13)-C(12)-C(11)-Z$ in bianthrones are measured.

As mentioned in the Introduction, the rationale provided by Mislow and co-workers for the gauche preference of bifluorenyl (7) is not applicable to bianthrones. We resorted to simpler model compounds to shed light on the roles played by structural units such as the central sixmembered ring and the flanking phenyl groups. Model-1 only contains the central six-membered ring of the bianthrone (Figure 2). We examined four conformers of Model-1 and their initial $\mathrm{H}-\mathrm{C}\left(\mathrm{sp}^{3}\right)-\mathrm{C}\left(\mathrm{sp}^{3}\right)-\mathrm{H}$ angles were $0^{\circ}, 60^{\circ}$ (gauche), $120^{\circ}$, and $180^{\circ}$ (anti). The gauche and anti conformers are local minima and the two eclipsed conformers are local maxima on the potential energy surface, with gauche being the global minimum. This energy profile is similar to that of $\mathbf{H - b i a . ~ A s ~ t h e ~}$ energy of the $0^{\circ}$ conformation is significantly higher than the $120^{\circ}$ conformation (Table 2 ), the conformation interconversion should be achieved by a gauche $\rightleftharpoons$ anti $\rightleftharpoons$ gauche process, rather than a direct gauche $\rightleftharpoons$ gauche process; this is also observed in the conformation interconversion of tetraalkylethanes. ${ }^{5 b}$ In the gauche confor-

(25) An edge-to-face relationship between OMe-bia and benzene is observed in the X-ray structure. In addition, weak $\mathrm{C}-\mathrm{H} \cdots \mathrm{O}(2.53 \AA$ for the $\mathrm{H} \cdots \mathrm{O}$ distance) interactions are present. (See Supporting Information.) mation of Model-1, the $\mathrm{C}\left(\mathrm{sp}^{3}\right)-\mathrm{C}\left(\mathrm{sp}^{3}\right)$ bond length is $1.581 \AA$ and the six-membered ring is nearly planar (flipping angle is $\left.1^{\circ}\right)$. This $\mathrm{C}\left(\mathrm{sp}^{3}\right)-\mathrm{C}\left(\mathrm{sp}^{3}\right)$ bond length is longer than that found in bifluorenyl (1.542 $\AA$ in X-ray structure and $1.562 \AA$ at the level of B 3 LYP/6-31G*). It may have some relevance with the close contact between $\mathrm{H}\left(\mathrm{sp}^{3}\right)$ and $\mathrm{C}\left(2^{\prime}\right)(2.63 \AA)$ of Model-1 (Figure $\left.4 a\right)$, which is shorter than that found in bifluorenyl $(2.75 \AA$ in X-ray and $2.72 \AA$ in the calculated structure). In the anti conformation the $\mathrm{C}\left(\mathrm{sp}^{3}\right)-\mathrm{C}\left(\mathrm{sp}^{3}\right)$ bond length is lengthened to $1.603 \AA$ and the flipping angle is significantly larger $\left(7.4^{\circ}\right)$ than in the gauche conformation. Two pairs of $\mathrm{H} \cdots \mathrm{H}$ contacts $(2.22 / 2.22 \AA)$ are present for the 2,6- and $2^{\prime}, 6^{\prime}$-hydrogen atoms in the anti form (Figure 4b). When we retained the $\mathrm{C}\left(\mathrm{sp}^{3}\right)-\mathrm{C}\left(\mathrm{sp}^{3}\right)$ bond length and flipping angle of the gauche conformer and rotated the central torsion to the anti form, the $\mathrm{H} \cdots \mathrm{H}$ contacts in this hypothetical structure were $1.96 / 2.00 \AA$, significantly less than the sum of van der Waals radius of $H(1.1 \AA)$. If we applied the $7.4^{\circ}$ flipping angle of the optimized anti structure to this hypothetical structure, the $\mathrm{H} \cdots \mathrm{H}$ contacts el ongated to $2.15 / 2.19 \AA$. No such $\mathrm{H} \cdots \mathrm{H}$ contact was found in the gauche form of Model-1. We propose that the anti conformer of Model-1 is of higher energy than 

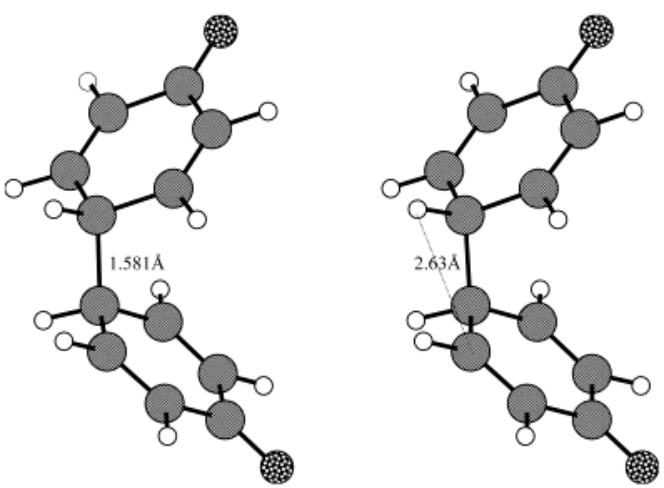

b
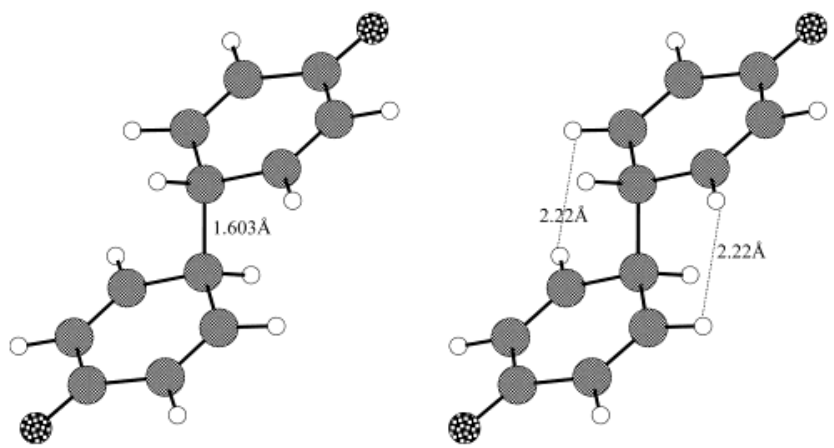

FIgURE 4. (a) Model-1 in the gauche conformation, with the $\mathrm{C}\left(\mathrm{sp}^{3}\right)-\mathrm{C}\left(\mathrm{sp}^{3}\right)$ bond length and distance between $\mathrm{H}\left(\mathrm{sp}^{3}\right)$ and $C\left(2^{\prime}\right)$ labeled. (b) Model-1 in the anti conformation, with the $\mathrm{C}\left(\mathrm{sp}^{3}\right)-\mathrm{C}\left(\mathrm{sp}^{3}\right)$ bond length and distance between $\mathrm{H} \cdots \mathrm{H}$ labeled.

the gauche because it suffers from more steric congestion that has to be relieved by bond elongation and loss of planarity of the six-membered ring to a larger extent.

In H-bia, C-H groups take the place of 2,2',6,6'-H atoms of Model-1 (Figure 2). Because the van der Waals radius of a $\mathrm{C}-\mathrm{H}$ group is larger than that of a $\mathrm{H}$ atom, it is not surprising that the $\mathrm{C}\left(\mathrm{sp}^{3}\right)-\mathrm{C}\left(\mathrm{sp}^{3}\right)$ bond and the central ring have to deform more seriously to accommodate the flanking phenyl groups. As shown in Table 2 the $\mathrm{C}\left(\mathrm{sp}^{3}\right)-\mathrm{C}\left(\mathrm{sp}^{3}\right)$ bond lengths of conformers of $\mathbf{H - b i a}$ are longer than $1.61 \AA$ and the flipping angles are larger than $20^{\circ}$, both significantly larger than corresponding values of Model-1. Similar to Model-1, the structural deformation (bond elongation and ring deformation) of H-bia is more severe in the anti conformer and its energy is higher than that of the gauche. Taking the " $\pi-\pi$ distance" as a measure of structural deformation around the $\mathrm{C}\left(\mathrm{sp}^{3}\right)-\mathrm{C}\left(\mathrm{sp}^{3}\right)$ bond, the extent of deformation is also larger in the anti conformer than the gauche for bianthrones $\mathbf{2} \mathbf{b}-\mathbf{5 b}$.

We have proposed that steric congestion contributes to the gauche preference of Model-1 and bianthrones based on the structural deformation in conformers. As deformation of the central six-membered ring is an important mechanism to fulfill the steric demand in the anti conformation (as well as in the two eclipsed local maxima), it is conceivable that one can control the energy difference between conformations by changing the flexibility of the central ring. We have changed the $Z$ group of the central ring from a carbonyl group to a methylene unit (Model-2 and bianthracene (8)) and to an oxygen atom (Model-3 and bixanthene (9)). (See F igure 2.) It is assumed that the $\mathrm{sp}^{2}$ carbonyl carbon conjugates more effectively with the adjacent double bonds than the other two $\mathrm{Z}$ groups do. Therefore, the six-membered ring in Model-1 and $\mathbf{H}$-bia should be more rigid than that in Model-2, Model-3, bianthracene, and bixanthene. It is shown in Table 2 that the range of flipping angle and the out-of-plane degree of Z (listed in parentheses under Flipping angle in Table 2) are indeed smaller for Model-1 $(\mathrm{Z}=\mathrm{CO})$ than for $\mathbf{M o d e l}-\mathbf{2}\left(\mathrm{Z}=\mathrm{CH}_{2}\right)$ and $\mathbf{M o d e l}-\mathbf{3}(\mathrm{Z}=$ $O)$. Meanwhile, since ring deformation can be achieved more easily when $\mathrm{Z}=\mathrm{CH}_{2}$ and $\mathrm{O}$, the need for el ongation of the $\mathrm{C}\left(\mathrm{sp}^{3}\right)-\mathrm{C}\left(\mathrm{sp}^{3}\right)$ bond becomes smaller in Model-2 and Model-3 than in Model-1. In accord with the concept that flexibility of the six-membered ring would affect the energy difference between conformers, the energy difference in $\mathbf{M o d e l - 1}$ is the largest among model compounds (Table 2). Compared to the model compounds, additional phenyl units are present in H-bia, bianthracene (8), and bixanthene (9). These additional structural units add in more complicated intramolecular interactions that would affect the anti-gauche energy difference. Nevertheless, the relatively rigid $\mathbf{H}$-bia still shows the largest anti-gauche energy difference (1.92 kal/ mol) among $\mathbf{H - b i a , ~ 8 , ~ a n d ~} \mathbf{9}$. In the gas phase, both 8 and 9 have small anti-gauche energy differences $(0.5$ and $0.4 \mathrm{kcal} / \mathrm{mol}$, respectively). F or $\mathbf{9}$ the gauche preference is enhanced by solvation, while for $\mathbf{8}$ the anti-gauche energy difference becomes vanishingly small after solvation treatment. This cal culated trend of loss of gauche preference in chloroform for $\mathbf{8}$, but not for $\mathbf{9}$, correlates well with the experimental results. ${ }^{7}$ For 8 the anti conformer is observed in crystal grown by a chloroform/ pentane mixture. Under the same experimental condition, the gauche conformer is observed for 9. (ORTEP drawings of $\mathbf{8}$ and $\mathbf{9}$ are shown in the Supporting Information.)

Finally, besides changing the flexibility of the central ring, one can certainly influence the gauche-anti energy differences by substituting the phenyl rings as in $\mathbf{C l - b i a ,}$ OMe-bia, $\mathbf{O H}-\mathbf{b i a}$, and $\mathbf{N H}_{\mathbf{2}}$-bia. However, since multiple factors (such as electronic effect, steric effect, specific interactions between the upper and lower decks of bianthrones, or even solvent or packing effects) are operative, it is very difficult to rationalize or to predict if a given substituent would provide a strong gauche or anti preference. For example, the position and electrondonating nature of substituents in $\mathbf{O H}$-bia and $\mathbf{N H}_{\mathbf{2}}$-bia are similar, but the degrees of gauche preference are very different. Nevertheless, our current calculation level affords reasonable results and should be useful in predicting preferred structures.

In summary, cal culation results at the B3LYP/6-31G* level are in line with experimental findings for bianthrones and related compounds, bianthracene and bixanthene. Studies of model compounds and observations of structural deformation involving bond elongation and nonplanarity reveal that steric congestion plays a role in structure and relative stability of gauche and anti conformers of bianthrones. Although all bianthrones studied here prefer the gauche conformation in the gas phase, the small gauche preference of $\mathbf{N H}_{\mathbf{2}}$-bia and 
OMe-bia can be overridden by solvent effects or packing forces. As the central six-membered ring is involved in relieving the steric effect, one can control the energy difference between gauche and anti conformation by changing the clamping group ( $Z$ ) to manipulate the flexibility of the central ring.

Acknowledgment. This work was supported by the National Science Council of Taiwan. We thank the National Center for High-Performance Computing and
Computing Center at Academia Sinica of Taiwan for allocation of computer time.

Supporting Information Available: Details of data collection, refinement parameters, and ORTEP drawings of $\mathbf{2 b}-\mathbf{5 b}, \mathbf{8}$, and $\mathbf{9}$; energies and Cartesian coordinates of all B3L YP/6-31G* calculated structures listed in Table 2 and of 7. This material is available free of charge via the Internet at http://pubs.acs.org.

J O020196G 